1 Revised on July 18, 2015

2

\title{
AC Power Generation from Microbial Fuel Cells
}

4

5

6

Fernanda Leite Lobo ${ }^{1}$, Heming Wang ${ }^{1}$, Casey Forrestal, Zhiyong Jason Ren ${ }^{*}$

7

Department of Civil, Environmental, and Architectural Engineering,

University of Colorado Boulder, Boulder, Colorado 80309

10

Corresponding author Ren E-mail: jason.ren@ colorado.edu

12

Phone: (303) 492-4137; Fax: (303) 492-7317

13

14

15

16

17

${ }^{1}$ These authors are equal contribution.

18

19

20

21 


\section{Abstract}

23 Microbial fuel cells (MFCs) directly convert biodegradable substrates to electricity and

24 carry good potential for energy-positive wastewater treatment. However, the low and

25 direct current (DC) output from MFC is not usable for general electronics except small

26 sensors, yet commercial DC-AC converters or inverters used in solar systems cannot be

27 directly applied to MFCs. This study presents a new DC-AC converter system for MFCs

28 that can generate alternating voltage in any desired frequency. Results show that AC

29 power can be easily achieved in three different frequencies tested $(1,10,60 \mathrm{~Hz})$, and no

30 energy storage layer such as capacitors was needed. The DC-AC converter efficiency was

31 higher than $95 \%$ when powered by either individual MFCs or simple MFC stacks. Total

32 harmonic distortion (THD) was used to investigate the quality of the energy, and it

33 showed that the energy could be directly usable for linear electronic loads. This study

34 shows that through electrical conversion MFCs can be potentially used in household

35 electronics for decentralized off-grid communities.

37 Keywords: Microbial fuel cell, DC-AC converter, AC power, Frequency. 


\section{$40 \quad$ Nomenclature}

$41 a_{h}, b_{h} \quad$ Fourier Coefficients (V)

$42 \quad$ Capacitance $(\mathrm{F})$

$43 f \quad$ Frequency $(\mathrm{Hz})$

44 FFT Fast Fourier Transform

$45 \quad h \quad$ Harmonic Order

$46 \quad I_{M F C} \quad$ MFC Current (I)

47 RMS Root Mean Square

$48 R_{\text {output }} \quad$ Output Resistor $(\Omega)$

$49 \quad$ Period (seconds)

$50 \quad V_{M F C} \quad$ MFC Voltage (V)

$51 V_{n} \quad \mathrm{~N}^{\text {th }}$ Harmonic Order Voltage (V)

$52 V_{\text {output }} \quad$ Output Voltage (V)

$53 \quad V(t) \quad$ Voltage function over time (V)

$54 \quad X_{c} \quad$ Capacitor Impedance $(\Omega)$

$55 \omega \quad$ Fundamental Frequency (radians)

56

57

58

59

60

61 


\section{1. Introduction}

64 The microbial fuel cell (MFC) technology has been intensively researched due to its

65 unique capability of converting any biodegradable substrates, especially waste materials,

66 into renewable electricity [1,2]. MFCs carry good potential to transform traditional

67 energy intensive wastewater treatment into energy-neutral or even energy-positive

68 processes, but it requires a quantum change in technological advances in scale, cost, and

69 practicality [3-5]. In addition to retrofit existing large-scale wastewater treatment, MFCs

70 can be an ideal waste treatment and renewable energy solution for decentralized or

71 remote villages in a nearer term, because it provides both energy and sanitation

72 infrastructures for these communities [6].

73 The technology downside is the low power production at current stage. Despite great

74 progress made in reactor configuration, material and operation that improved power

75 output from $1 \mathrm{~mW} \mathrm{~m}^{-2}$ to about $19 \mathrm{~W} \mathrm{~m} \mathrm{~m}^{-2}$, the voltage provided by MFCs is still in the

76 order of $\mathrm{mV}$ [7]. This is why energy harvesting using power electronics is crucial to make

77 MFC application relevant. To date all efforts in MFC energy harvesting have been

78 focusing on direct current (DC) output using DC-DC converters [8-10], capacitor

79 charging and discharging [11-13] and power management systems [14,15]. These

80 systems have been developed to boost the voltage to power small electronic devices such

81 as hydrophones or sensors [14,16,17], and a recent study provides a comprehensive

82 review of the current status and future need of practical energy harvesting from MFCs [7].

83 While in many cases DC output is sufficient for MFC-powered sensor applications,

84 alternating current (AC) power generation is needed for community waste treatment and 
85 power solutions, because general household electrical appliances require AC power to

86 operate, and the electrical grid distributes the electricity in the form of AC. Other

87 renewable energy source such as Solar also produces DC power, which is then converted

88 to $\mathrm{AC}$ power using inverter or DC-AC converter. The DC-AC converters are

89 commercially sold but require an input voltage of at least $12 \mathrm{~V}$ [18], far beyond MFC

90 voltage output level.

91 Though AC power generation from MFCs has not been reported so far, it becomes an

92 imminent need for larger scale MFC development to meet real-world requirements. In

93 this study, AC power generation was realized from MFCs through the development of a

94 DC-AC converter system, and AC power in different frequencies with different MFC

95 input voltages were also investigated. In addition, the quality of energy and the efficiency

96 of the converter were also examined. Different frequency and quality investigations are

97 important because unlike DC power, AC power outputs vary among different regions in

98 the world. For example, Europe adopts an AC standard of 220-240 volts at $50 \mathrm{~Hz}$, while

99 North America uses 120 volts at $60 \mathrm{~Hz}$.

100

101 2. Materials and Methods

\section{$102 \quad 2.1$ MFC construction and operation}

103 Single-chamber MFCs were built by one polycarbonate cube-shaped chamber with an

104 empty volume of $28 \mathrm{~mL}$. A heat-treated graphite brush was used as the anode, and $30 \%$

105 water-proof carbon cloth $\left(7 \mathrm{~cm}^{2}\right.$, Fuel Cell Earth) was as the air-cathode, which

106 composed of one carbon base layer, four polytetrafluoroethylene diffusion layers and one

107 catalyst layer $\left(0.5 \mathrm{mg} \mathrm{Pt} \mathrm{cm}^{-2}\right)$ [19]. MFCs were inoculated with anaerobic sludge 
108 obtained from the Boulder Water Resource Recovery Facility. The growth medium

109 contains (per liter) $1.0 \mathrm{~g} \mathrm{CH}_{3} \mathrm{COONa}, 0.31 \mathrm{~g} \mathrm{NH}_{4} \mathrm{Cl}, 0.13 \mathrm{~g} \mathrm{KCl}, 3.32 \mathrm{~g} \mathrm{NaH}_{2} \mathrm{PO}_{4} .2 \mathrm{H}_{2} \mathrm{O}$,

$11010.32 \mathrm{~g} \mathrm{Na}_{2} \mathrm{HPO}_{4} .12 \mathrm{H}_{2} \mathrm{O}, 12.5 \mathrm{~mL}$ mineral solution, and $5 \mathrm{~mL}$ vitamin solution [20].

111 Fresh medium was refilled every $24 \mathrm{~h}$. All MFCs were run in duplicate in batch mode at 112 room temperature.

113

\section{$114 \quad 2.2 \mathrm{DC}$ to AC circuit design and control}

115 The custom-designed DC-AC converter is able to transform MFC DC power output

116 to AC output (Figure 1). The DC-AC converter consists of MFCs (MFC1 and MFC2) as

117 the DC power sources, capacitors (C1 and $\mathrm{C} 2,1000 \mu \mathrm{F})$ as the intermediate energy

118 storage, and MOSFETs (M1 and M2, NTD4906N) as switches. The switches M1 and M2

119 were alternately controlled ON/OFF in order to create positive and negative parts of the

120 AC outputs. The control signals to switch ON/OFF were programmed by an Arduino

121 microcontroller (Uno, R2) which was connected to a laptop. A binary value of 1 (5 V)

122 assigned by the Arduino turns on the MOSFET while a binary value of $0(0 \mathrm{~V})$ turns off

123 the MOSFET. Since the control signal is a pulse with a period $(T)$ that is equal to the sum

124 of $T_{O N}$ and $T_{O F F}$, and the period of a signal is the inverse of the frequency $(f)$ or $T=1 / f$,

125 it can be derived that $T_{O N}=T_{O F F}=1 / 2 f$. The DC-AC converter was tested in different 126 conditions, including three different frequencies $(1 \mathrm{~Hz}, 10 \mathrm{~Hz}$ and $60 \mathrm{~Hz})$, absence or

127 presence of energy storage layers (capacitors), and powered by 2 MFCs or 4 MFCs 128 paired in series. Serial MFC connection provides higher voltages and more power for the 129 DC-AC converter. 
132 The control signals for M1 and M2, the voltages and electrode potentials of the MFCs,

133 the output voltage of the DC-AC converter, and the current in the circuit were all

134 measured using an Oscilloscope (Agilent Technologies, DS01024A). MFC polarization

135 curves were measured by varying external resistors from open circuit to $50 \Omega$ using a

136 resistor box.

137 To evaluate the efficiency of the DC-AC converter, a $100 \mathrm{k} \Omega$ resistor was used as the 138 output load to close the circuit but simulate open circuit condition. The efficiency of the

139 DC-AC converter was calculated by Equation (1):

$140 \quad \eta=\frac{V_{\text {output }}{ }^{2}}{R_{\text {output }}} \frac{1}{V_{M F C} I_{M F C}} 100 \%$

141 where $V_{\text {output }}$ is the root mean square (RMS) value of the AC output voltage that 142 represents the usable voltage in $\mathrm{AC}$, since the output voltage is a square wave, its RMS

143 value is the same as the maximum value [21]; $R_{\text {output }}$ is the output resistor which equals

$144100 \mathrm{k} \Omega ; V_{M F C}$ and $I_{M F C}$ are the voltage and current from the MFC, respectively, and $I_{M F C}$

145 is the same as the current passing through the output resistor $(100 \mathrm{k} \Omega$ ) (Figure $1 \mathrm{~B}$ and

146 1C). Using an electrochemical workstation may provide more accurate $I_{M F C}$ value and

147 such method will be performed in future studies.

\section{3. Results and discussion}

$150 \quad 3.1$ Operation of the DC-AC Converter under Different Frequencies

151 The DC-AC converter was operated by an Arduino microcontroller, which generates 152 control signals to turn ON or OFF the MOSFETs at desired frequencies $(1 \mathrm{~Hz}, 10 \mathrm{~Hz}$, or $15360 \mathrm{~Hz}$ in this study). Figure 1A shows the schematic diagram of the DC-AC converter. 
154 When M1 is ON and M2 is OFF, the DC voltage from MFC1 passes through while the

155 DC voltage from MFC2 is cut off, so the MFC1 DC voltage is mirrored as the positive

156 part of the AC voltage (Figure 1B); In contrast, when M1 is OFF and M2 is on, DC

157 voltage in opposite direction is generated from M2 through the converter, which is

158 mirrored as the negative part of the AC voltage (Figure 1C). As a result, the output

159 voltages of the DC-AC converter continuously alternate between positive and negative

160 voltages in periodic cycles, that is, AC voltages.

161 To test the feasibility of applying different frequencies, control signals for each

162 MOSFET (M1 and M2) were operated at frequencies of $1 \mathrm{~Hz}, 10 \mathrm{~Hz}$ and $60 \mathrm{~Hz}$ (Figure

163 2). The frequency of $60 \mathrm{~Hz}$ (Figure 2C) is the primary goal because most electric loads

164 are operated at $60 \mathrm{~Hz} \mathrm{AC}$. The frequencies of $1 \mathrm{~Hz}$ (Figure 2A) and $10 \mathrm{~Hz}$ (Figure 2B)

165 were chosen to demonstrate that the DC-AC converter can work at various frequencies

166 under different MFC performance. All the control signals are periodic square waves with

167 a period of $T=1 / f$, where half of the period $\left(T_{O N}\right)$ has a binary value of $1(5 \mathrm{~V})$ and the

168 other half of the period $\left(T_{O F F}\right)$ has a binary value of $0(0 \mathrm{~V})$. Since the period of the 169 control signal depends on the frequency, the period decreased from $1 \mathrm{~Hz}$ to $60 \mathrm{~Hz}$, as 170 shown in Figure 2A-C.

171

\section{3.2 AC Power Output without Using Energy Storage Layer (Capacitors)}

173 Most MFC harvesting systems use energy storages, such as capacitors, due to the low 174 direct energy output from MFCs. For this experiment, the energy storage layer was 175 avoided in order to simplify the circuit and investigate if MFCs can power DC-AC 176 converter directly and effectively (Figure 3). Two MFCs or four MFCs (2 groups of 2 
177 MFCs in series) were used as the direct DC power inputs. Without using capacitors as the

178 energy storage layer, DC power from MFCs was successfully transformed to AC power.

179 The AC voltage outputs kept square-shaped waves at $1 \mathrm{~Hz}$ and $10 \mathrm{~Hz}$ and only slightly

180 deformed at $60 \mathrm{~Hz}$. The input DC voltages and the output AC voltages both dropped

181 gradually with increasing the frequency from $1 \mathrm{~Hz}$ to $60 \mathrm{~Hz}$, but the output AC voltages

182 were always comparable to the input DC voltages. When the DC-AC converter was

183 powered by two MFCs, the positive AC outputs decreased along with the increase of

184 frequency. For example, the AC outputs decreased from $720 \mathrm{mV}(1 \mathrm{~Hz})$ to $680 \mathrm{mV}(10$

$185 \mathrm{~Hz})$ and then to $480 \mathrm{mV}(60 \mathrm{~Hz})$, and the absolute values of the negative AC outputs

186 decreased from $600 \mathrm{mV}(1 \mathrm{~Hz})$ to $560 \mathrm{mV}(10 \mathrm{~Hz})$ and then to $400 \mathrm{mV}(60 \mathrm{~Hz})$. Similar

187 trend was observed under 4-MFC conditions, with the positive AC outputs decreased

188 from $1480 \mathrm{mV}(1 \mathrm{~Hz})$ to $1280 \mathrm{mV}(10 \mathrm{~Hz})$ and $1000 \mathrm{mV}(60 \mathrm{~Hz})$, and the absolute values

189 of the negative AC outputs decreased from $1320 \mathrm{mV}(1 \mathrm{~Hz})$ to $1160 \mathrm{mV}(10 \mathrm{~Hz})$ and 880

$190 \mathrm{mV}(60 \mathrm{~Hz})$.

191 The slope of the linear section on the polarization curve has been widely used to

192 determine the internal resistance of the direct output of an MFC [22]. Similar concepts

193 can be adopted in AC condition. Figure S1 shows that the polarization curves under

194 different frequencies can be considered as parallel lines without significant slope changes,

195 which means that the internal resistances of MFC1 and MFC2 kept consistent when

196 energy-harvesting frequencies changed. The internal resistances of MFC1 and MFC2

197 were estimated as $41.7 \pm 1 \Omega$ and $48 \pm 2 \Omega$ at the three frequencies, respectively.

$198 \quad$ MFC anode and cathode potentials were measured to investigate the influence of

199 frequencies on the MFC voltage. When the frequency increased from $1 \mathrm{~Hz}$ to $10 \mathrm{~Hz}$ then 
200 to $60 \mathrm{~Hz}$, anode potentials were comparable while cathode potentials significantly

201 dropped. The open circuit cathode potentials of MFC1 and MFC2 decreased from 232

$202 \mathrm{mV}$ to $88 \mathrm{mV}$ and from $216 \mathrm{mV}$ to $48 \mathrm{mV}$, respectively, while the open circuit anode

203 potentials remained at $464 \pm 20 \mathrm{mV}$ for all the three frequencies (Figure 4). The

204 comparable anode potentials among different frequencies suggested that enough electrons

205 were available for current generation because of the capacitive properties of the anodic

206 biofilm $[23,24]$. The decrease of cathode potentials is hypothesized due to local $\mathrm{pH}$

207 increase, which were reported by previous studies that $\mathrm{OH}^{-}$accumulation on the Pt-based

208 air cathode can cause a potential loss up to 0.3V [25]. During higher frequency energy-

209 harvesting, the transport of $\mathrm{OH}^{-}$to the bulk electrolyte is slower than lower frequencies

210 because of the smaller $T_{O N}$ and $T_{O F F}$, which may cause potential drop due to limited mass

211 transfer. No pH change was observed in bulk solution due to the use of buffer solution,

212 but more studies are needed to further investigate the cathode potential drops at different

213 energy-harvesting frequencies with local $\mathrm{pH}$ measurements on the electrode surface.

\section{3.3 AC Power Output with Energy Storage Layer (Capacitors)}

216 To compare with the results without using energy storage layer, in following studies

217 we added capacitors in the circuit as temporary energy storage to transform DC power

218 from MFCs to AC power outputs from the converter. Similar MFC connections were

219 used (2 MFCs or 4 MFCs in $2 \times 2$ serial connection), but the results in terms of shape and

220 magnitude are very different between the two scenarios with or without capacitors

221 (Figure 3 vs. Figure 5). Compared with regular shaped AC square waves when no

222 capacitors were used, the input and output waves were distorted at even $1 \mathrm{~Hz}$ when 
223 capacitors were present and the waves became even indistinguishable at $60 \mathrm{~Hz}$. In

224 addition, the input DC voltages and output AC voltages dropped significantly with

225 capacitors in the circuit from $1 \mathrm{~Hz}$ to $60 \mathrm{~Hz}$. The positive AC outputs decreased from 680

$226 \mathrm{mV}(1 \mathrm{~Hz})$ to $120 \mathrm{mV}(60 \mathrm{~Hz})$ when powered by $2 \mathrm{MFCs}$ and from $1160 \mathrm{mV}(1 \mathrm{~Hz})$ to -

$22740 \mathrm{mV}(60 \mathrm{~Hz})$ when powered by 4 MFCs. The absolute values of the negative AC

228 outputs decreased from $600 \mathrm{mV}(1 \mathrm{~Hz})$ to $40 \mathrm{mV}(60 \mathrm{~Hz})$ when powered by $2 \mathrm{MFCs}$ and

229 from $1040 \mathrm{mV}(1 \mathrm{~Hz})$ to $160 \mathrm{mV}(60 \mathrm{~Hz})$ when powered by $4 \mathrm{MFCs}$.

230 When comparing the output AC voltages at the same frequency, we found that the

231 AC outputs were much lower when capacitors were used, especially under the conditions

232 of higher frequencies. At $1 \mathrm{~Hz}$, the output voltage decreased only $40 \mathrm{mV}$ (from $720 \mathrm{mV}$

233 to $680 \mathrm{mV}$ ) when the DC-AC converter was powered by $2 \mathrm{MFCs}$ (Figure 3A vs. 5A), and

234 a higher drop was observed (320 mV) when 4 MFCs were used (Figure 3D vs. 5D). At 10

$235 \mathrm{~Hz}$, such drops increased to $320 \mathrm{mV}$ (2 MFCs) and $1000 \mathrm{mV}$ (4 MFCs), respectively

236 (Figure 3B vs. 5B, Figure 3E vs. 5E). Similarly, even bigger drops were observed under

$23760 \mathrm{~Hz}$, with $360 \mathrm{mV}$ and $1400 \mathrm{mV}$ dropped under the 2-MFC or 4-MFC condition,

238 respectively. (Figure 3C vs. 5C, Figure 3F vs. 5F).

239 The big drop of output AC voltage when capacitors were added was believed due to

240 the impedance of capacitors at different frequencies. The impedance of a capacitor $(X c)$

241 changes according to the frequency $(f, \mathrm{~Hz})$ and its capacitance $(C, \mathrm{~F})$, with the

242 relationship expressed as [26]

$243 \quad X c=\frac{1}{2 \pi f C}$

244 When the frequency increases from $1 \mathrm{~Hz}$ to $10 \mathrm{~Hz}$ and $60 \mathrm{~Hz}$, the impedance of the 245 capacitor decreases from $X c_{1 \mathrm{~Hz}}=160 \Omega$ to $X c_{10 \mathrm{~Hz}}=16 \Omega$, and then to $X c_{60 \mathrm{~Hz}}=2.6 \Omega$, 
246 based on Equation 2. The capacitor works as a low-pass filter as it cuts the voltage

247 components for the higher frequencies and let only the voltage components of the low

248 frequency pass through [26]. The low-pass filter is a voltage divider between the

249 resistance of the circuit and the impedance of the capacitor (Supporting Information for

250 more details). Therefore, the voltage across the capacitor, which is mirrored to the output

251 voltage, drops along the decreasing impedance and increasing frequencies. To avoid this

252 performance drop, the capacitor should be determined according to the desired frequency.

253 For instance, if the desired frequency is $60 \mathrm{~Hz}$, a capacitor with a smaller capacitance of

254 around $20 \mu \mathrm{F}$ should be chosen to create a greater impedance of around $160 \Omega$. This

255 study chose a capacitor of $1000 \mu \mathrm{F}$, which is more compatible with $1 \mathrm{~Hz}$, and that's why

256 less drop was found under $1 \mathrm{~Hz}$ while large drop was found under $60 \mathrm{~Hz}$.

258 3.4 AC Power Quality from MFCs

259 In conventional AC electric energy systems, the voltage generated is a sine wave

260 form with a frequency of $60 \mathrm{~Hz}$ (U.S.). During the transformation from renewable DC

261 power to AC power, like those from solar panels or MFCs in this study, the power quality,

262 expressed as total harmonic distortion (THD) at $60 \mathrm{~Hz}$, depends on how the AC voltage

263 generated via the DC-AC converter differs from the conventional $60 \mathrm{~Hz}$ sine wave

264 voltages. In other words, the power quality is related to the quantity of harmonics in the

265 AC voltage generated via the DC-AC converter. A harmonic is a sinusoidal waveform

266 with a frequency that is an integral multiple of the fundamental frequency of $60 \mathrm{~Hz}$ [27].

267 The THD measures the quantity of harmonics of a wave by using Fourier analysis, via

268 which any periodic waveforms can be described as an infinite sum of sine waves in 
269 different frequencies (Supporting Information for more details). Since the output voltage

270 from the DC-AC converter is a periodic waveform with period $T$, thus it can be described

271 as [21]

$272 \quad V(t)=\frac{1}{T} \int_{0}^{T} V(t) d t+\sum_{h=1}^{h=+\infty}\left[a_{h} \cos (h \omega t)+b_{h} \sin (h \omega t)\right]$

273 where $h$ is the harmonic order, $\omega$ is the fundamental frequency that is equal to $2 \pi / T$ and $274 \quad a_{h}$ and $b_{h}$ are given by

$275 \quad a_{h}=\frac{2}{T} \int_{0}^{T} V(t) \cos (h \omega t) d t$

$276 \quad b_{h}=\frac{2}{T} \int_{0}^{T} V(t) \sin (h \omega t) d t$

277 The harmonic order is the multiple of the fundamental frequency, for instance, the second 278 harmonic for a fundamental frequency of $60 \mathrm{~Hz}$ is at the frequency of $120 \mathrm{~Hz}$.

279 The Fast Fourier Transform (FFT) is an algorithm that represents the Fourier analysis 280 in the frequency domain, which can easily provide the voltage in each harmonic. The 281 THD is measured by [21]

$282 T H D=\frac{\sqrt{V_{2}^{2}+V_{3}{ }^{2}+V_{4}{ }^{2}+\ldots+V_{n}^{2}}}{V_{1}} 100 \%$

283 where $V_{l}$ is the voltage in the fundamental frequency, $V_{2}$ is the voltage in the second 284 harmonic, $V_{3}$ is the voltage in the third harmonic and so on.

285 The FFT of the output voltages were measured when the DC-AC converter was 286 powered by 2MFCs (Figure 6A) or 4 MFCs (Figure 6B) at $60 \mathrm{~Hz}$, which is the standard 287 frequency of AC in the electric power grid in the U.S. When the DC-AC converter was 288 powered by 2 MFCs, the most relevant harmonic was the third harmonic, where the 289 frequency $(180 \mathrm{~Hz})$ was three times as the fundamental frequency. The corresponding 290 THD of the output voltage was around 30\%. When 4 MFCs were used, the most relevant 
291 harmonics were the second $(120 \mathrm{~Hz})$ and third harmonic $(180 \mathrm{~Hz})$, with a relevant THD

292 around $30 \%$ as well. The THD standard for grid-tied systems is $8 \%$ [28], but for stand-

293 alone renewable systems the square-wave DC-AC converter with a THD of 30\%, like the

294 one developed here, can be used to power linear loads safely [21].

\section{3.5 The efficiency of the DC-AC converter}

297 The efficiency of the DC-AC converter was calculated without using the capacitors in

298 the circuit (Figure 7). The custom-designed DC-AC converter was very efficient with the

299 efficiencies reached almost $100 \%$ in repeated tests. The efficiencies of the DC-AC

300 converter among various frequencies $(1 \mathrm{~Hz}, 10 \mathrm{~Hz}$, and $60 \mathrm{~Hz})$ were around $97 \pm 3 \%$, with

301 the limited energy losses mainly due to the MOSFET conduction loss and the switching

302 loss. When the frequencies increased from $1 \mathrm{~Hz}$ to $60 \mathrm{~Hz}$, the efficiencies decreased

303 because more energy was lost on the MOSFET switches at the high switching frequency,

304 but the energy loss was still small. When the DC-AC converter was powered by 4 MFCs

305 instead of 2 MFCs, the average efficiencies were slightly higher $(99 \pm 1 \%)$ due to higher

306 voltage and more power provided. This result encourages the potential that if enough

307 MFCs connected in series to provide a DC voltage of $110 \mathrm{~V}$, the energy loss can be

308 manageable. Since the microcontroller was not the focus in this study, the overall

309 efficiency of the circuit including the extra power for Arduino was not investigated.

\subsection{Discussion}

312 This study proves that AC power can be efficiently generated from microbial fuel

313 cells, and different frequencies can be varied depending on the needs of electronic loads. 
314 The first DC-AC converter for MFCs has efficiency above 95\%, which can assist the

315 development of MFC systems for power and sanitation solutions for decentralized

316 communities. Although the low voltage provided directly from MFCs is not enough to

317 power an electric load, this study shows that MFC stacks may be able to do so without

318 significant energy loss. In addition, transformers can be coupled at the output of the DC-

319 AC converter to boost the voltage to a usable level.

320 However, many challenges remain before large-scale systems can be developed to

321 power electric loads, such as potential voltage reversal in MFC stacks and more

322 efficiency energy harvesting from MFC reactors. Maximum power point tracking (MPPT)

323 algorithms and many other approaches are being investigated to solve these problems

324 [29,30]. In addition, the voltage output in this studied DC-AC converter topology is based

325 on a mirror control of the input voltage provided by the MFC. By using a different

326 control scheme like modified sine-wave Pulse Width Modulation (PWM), the quality of

327 energy output can be even higher. Also, because MFC DC voltage output can vary

328 constantly due to the change of environmental conditions, a closed loop control in the

329 converter may be applied to improve the output voltage stability.

\section{Acknowledgement}

332 We thank the financial support from CAPES (Science without Borders) for FLL and

333 Office of Naval Research (Award N000141310901) for HW and ZJR.

\section{References}

336 [1] B. Logan, K. Rabaey, Conversion of wastes into bioelectricity and chemicals by 337 using microbial electrochemical technologies, Science 337 (2012) 686-690. 
[2] H. Wang, Z.J. Ren, A comprehensive review of microbial electrochemical systems as a platform technology., Biotechnol. Adv. 31 (2013) 1796-807.

[3] R. a Rozendal, H.V.M. Hamelers, K. Rabaey, J. Keller, C.J.N. Buisman, Towards practical implementation of bioelectrochemical wastewater treatment., Trends Biotechnol. 26 (2008) 450-9.

[4] T.H.J.A. Sleutels, A. Ter Heijne, C.J.N. Buisman, H.V.M. Hamelers, Bioelectrochemical systems: An outlook for practical applications, ChemSusChem. 5 (2012) 1012-1019.

[5] H. Wang, H. Luo, P.H. Fallgren, S. Jin, Z.J .Ren, Bioelectrochemical system platform for sustainable environmental remediation and energy generation, Biotechnol. Adv. 33 (2015) 317-334.

[6] H. Yazdi, L. Alzate-Gaviria, Z.J. Ren, Pluggable microbial fuel cell stacks for septic wastewater treatment and electricity production, Bioresour. Technol. 180 (2015), 258-263.

[7] H. Wang, J.-D. Park, Z.J. Ren, Pratical energy harvesting for microbial fuel cells: a review., Environ. Sci. Technol. 49 (2015) 3267-3277.

[8] N. Degrenne, B. Allard, F. Buret, S.-E. Adami, D. Labrousse, C. Vollaire, et al., A $140 \mathrm{mV}$ Self-Starting $10 \mathrm{~mW}$ DC/DC Converter for Powering Low-Power Electronic Devices from Low-Voltage Microbial Fuel Cells, J. Low Power Electron. 8 (2012) 485-497.

[9] J.-D. Park, Z. Ren, Hysteresis-controller-based energy harvesting scheme for microbial fuel cells with parallel operation capability, Energy Conversion, IEEE Transactions, 27 (2012), 715-724

[10] N. Degrenne, F. Buret, F. Morel, S.E. Adami, D. Labrousse, B. Allard, et al., Selfstarting DC:DC boost converter for low-power and low-voltage microbial electric generators, in: IEEE Energy Convers. Congr. Expo. Energy Convers. Innov. a Clean Energy Futur. ECCE 2011, Proc., 2011: pp. 889-896.

[11] A. Dewan, H. Beyenal, Z. Lewandowski, Intermittent energy harvesting improves the performance of microbial fuel cells., Environ. Sci. Technol. 43 (2009) 46004605.

[12] P. Liang, W. Wu, J. Wei, L. Yuan, X. Xia, X. Huang, Alternate charging and discharging of capacitor to enhance the electron production of bioelectrochemical systems., Environ. Sci. Technol. 45 (2011) 6647-53.

[13] S. Ren, X. Xia, L. Yuan, P. Liang, X. Huang, Enhancing charge harvest from microbial fuel cells by controlling the charging and discharging frequency of capacitors, Bioresour. Technol. 146 (2013) 812-815.

[14] M. Alaraj, Z.J. Ren, J.-D. Park, Microbial fuel cell energy harvesting using synchronous flyback converter, J. Power Sources. 247 (2014) 636-642.

[15] C. Donovan, A. Dewan, H. Peng, D. Heo, H. Beyenal, Power management system for a $2.5 \mathrm{~W}$ remote sensor powered by a sediment microbial fuel cell, J. Power Sources. 196 (2011) 1171-1177.

[16] Y. Gong, S.E. Radachowsky, M. Wolf, M.E. Nielsen, P.R. Girguis, C.E. Reimers, Benthic microbial fuel cell as direct power source for an acoustic modem and seawater oxygen/temperature sensor system, Environ. Sci. Technol. 45 (2011) $5047-5053$. 
[17] A. Shantaram, H. Beyenal, R. Raajan, A. Veluchamy, Z. Lewandowski, Wireless sensors powered by microbial fuel cells., Environ. Sci. Technol. 39 (2005) 50375042.

[18] ABB micro inverter system, (n.d.). http://www05.abb.com/global/scot/scot232.nsf/veritydisplay/7efd88eadccaa1c585 257dc5006e334e/\$file/MICRO-0.25-0.3-0.3HV-Rev1.6.pdf. (acessed December 10, 2014).

[19] H. Wang, D. Heil, Z.J. Ren, P. Xu, Removal and fate of trace organic compounds in microbial fuel cells., Chemosphere. 125 (2015) 94-101.

[20] H. Zhu, H. Wang, Y. Li, W. Bao, Z. Fang, C. Preston, et al., Lightweight, conductive hollow fibers from nature as sustainable electrode materials for microbial energy harvesting, Nano Energy 10 (2014) 268-276.

[21] R.W. Erickson, D. Maksimovic, Fundamentals of Power Electronics, Second Ed., Kluwer Academic Publishers, New York, 2001.

[22] B.E. Logan, B. Hamelers, R. Rozendal, U. Schroder, Microbial Fuel Cells : Methodology and Technology, Environ. Sci. Technol. 40 (2006) 5181-5192.

[23] H. Wang, Z. Ren, J.-D. Park, Power electronic converters for microbial fuel cell energy extraction: Effects of inductance, duty ratio, and switching frequency, $\mathrm{J}$. Power Sources. 220 (2012) 89-94.

[24] Z. Lu, P. Girguis, P. Liang, H. Shi, G. Huang, L. Cai, et al., Biological capacitance studies of anodes in microbial fuel cells using electrochemical impedance spectroscopy., Bioprocess Biosyst. Eng. 38 (2015) 1325-1333.

[25] X. Wang, C. Feng, N. Ding, Q. Zhang, Accelerated OH-Transport in Activated Carbon Air Cathode by Modification of Quaternary Ammonium for Microbial Fuel Cells, Environ. Sci. Technol. 48 (2014) 4191-4198.

[26] C.K. Alexander, M.N.O. Sadiku, Fundamentals of Electric Circuit, Fifth Edit, McGraw-Hill, New York, 2013.

[27] R.D. Henderson, P.J. Rose, Harmonics: The Effects on Power Quality and Transformers, IEEE Trans. Ind. Appl. 30 (1994).

[28] D. Committee, I. Power, E. Society, IEEE Recommended Practice and Requirements for Harmonic Control in Electric Power Systems IEEE Power and Energy Society, 2014 (2014).

[29] H.C. Boghani, G. Papaharalabos, I. Michie, K.R. Fradler, R.M. Dinsdale, A.J. Guwy, et al., Controlling for peak power extraction from microbial fuel cells can increase stack voltage and avoid cell reversal, J. Power Sources. 269 (2014) 363369.

[30] H. Wang, J.-D. Park, Z. Ren, Active energy harvesting from microbial fuel cells at the maximum power point without using resistors., Environ. Sci. Technol. 46 (2012) 5247-52. 


\section{$431 \quad$ Figure Captions}

Figure 1: (A) Circuit diagram of the DC-AC converter system for MFCs; (B) equivalent circuit diagram when MOSFET M1 is ON and MOSFET M2 is OFF to output the positive part of AC; (C) equivalent circuit diagram when MOSFET M1 is OFF and MOSFET M2 is ON to output the negative part of AC.

Figure 2: Control signals at $1 \mathrm{~Hz}(\mathrm{~A}), 10 \mathrm{~Hz}$ (B) and $60 \mathrm{~Hz}(\mathrm{C})$. The blue curve is the control signal for MOSFET M1 and the magenta curve is the control signal for MOSFET M2.

Figure 3: Input and output voltages without using energy storage layer (capacitors) in the circuit. The DC-AC converter was powered by two MFCs at $1 \mathrm{~Hz}(\mathrm{~A}), 10 \mathrm{~Hz}$ (B) and 60 $\mathrm{Hz}(\mathrm{C})$ or four MFCs (2 groups of 2 MFCs in series) at $1 \mathrm{~Hz}(\mathrm{D}), 10 \mathrm{~Hz}(\mathrm{E})$ and $60 \mathrm{~Hz}(\mathrm{~F})$. Blue waves: MFC1; magenta waves: MFC2; green waves: AC output.

Figure 4: Electrode potential changes of MFC1 (A) and MFC2 (B) at frequencies of $1 \mathrm{~Hz}, 10 \mathrm{~Hz}$ and $60 \mathrm{~Hz}$ without using capacitors in the circuit.

Figure 5: Input and output voltages when using energy storage layer (capacitors) in the circuit. The DC-AC converter was powered by two MFCs at $1 \mathrm{~Hz}(\mathrm{~A}), 10 \mathrm{~Hz}$ (B) and 60 $\mathrm{Hz}(\mathrm{C})$ or four MFCs (2 groups of $2 \mathrm{MFCs}$ ) in series at $1 \mathrm{~Hz}(\mathrm{D}), 10 \mathrm{~Hz}(\mathrm{E})$ and $60 \mathrm{~Hz}(\mathrm{~F})$. Blue waves: MFC1; magenta waves: MFC2; green waves: AC output.

Figure 6: Output voltages and the Fast Fourier Transform (FFT) of the output voltages at $60 \mathrm{~Hz}$ when the DC-AC converter was powered by two MFCs (A) and four MFCs (2 groups of 2 MFCs in series) (B).

Figure 7: Efficiency of the DC-AC converter powered by two or four MFCs (2 groups of 461 


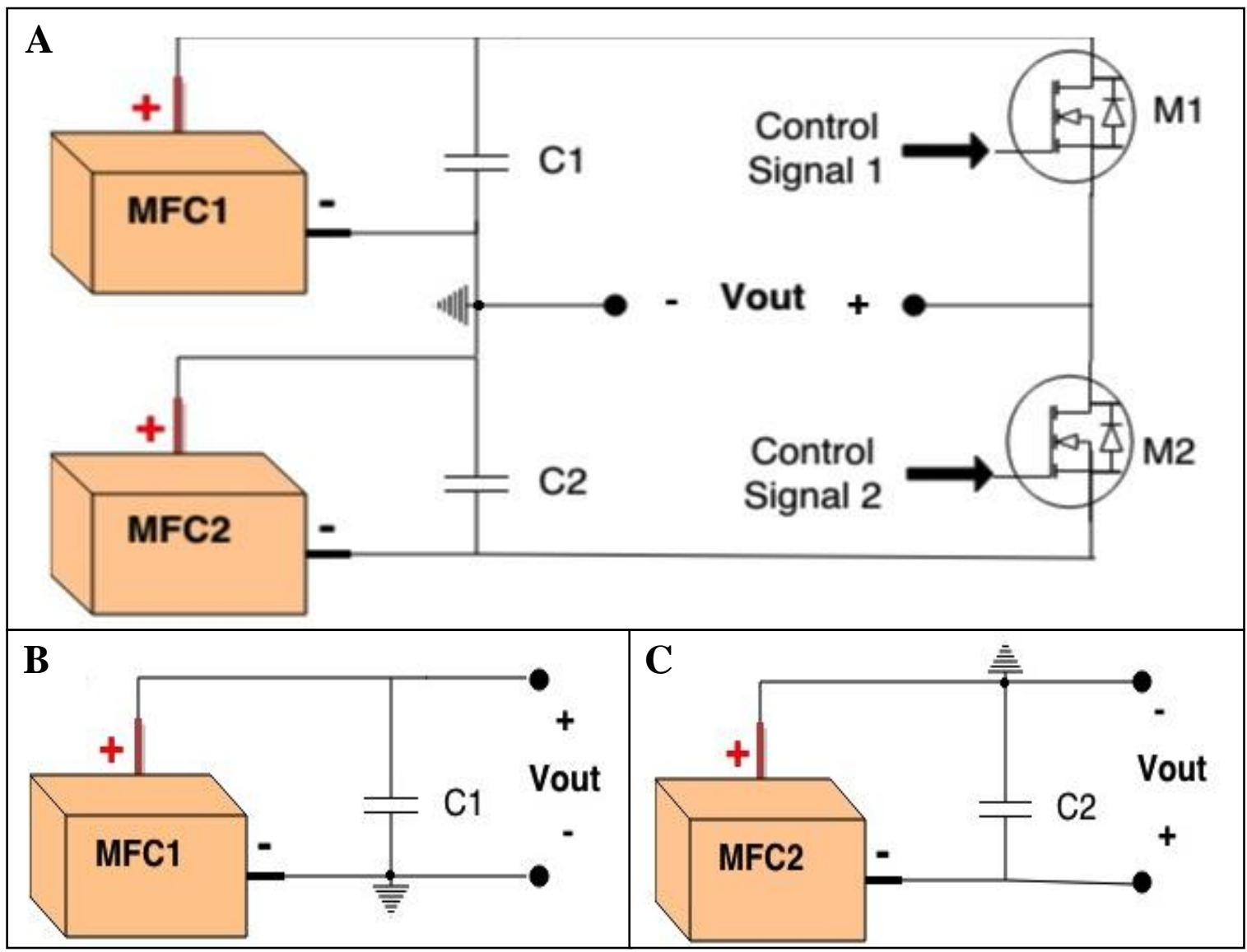

Figure 1 (A) Circuit diagram of the DC-AC converter system for MFCs; (B) equivalent circuit diagram when MOSFET M1 is ON and MOSFET M2 is OFF to output the positive part of $\mathrm{AC}$; (C) equivalent circuit diagram when MOSFET M1 is OFF and 

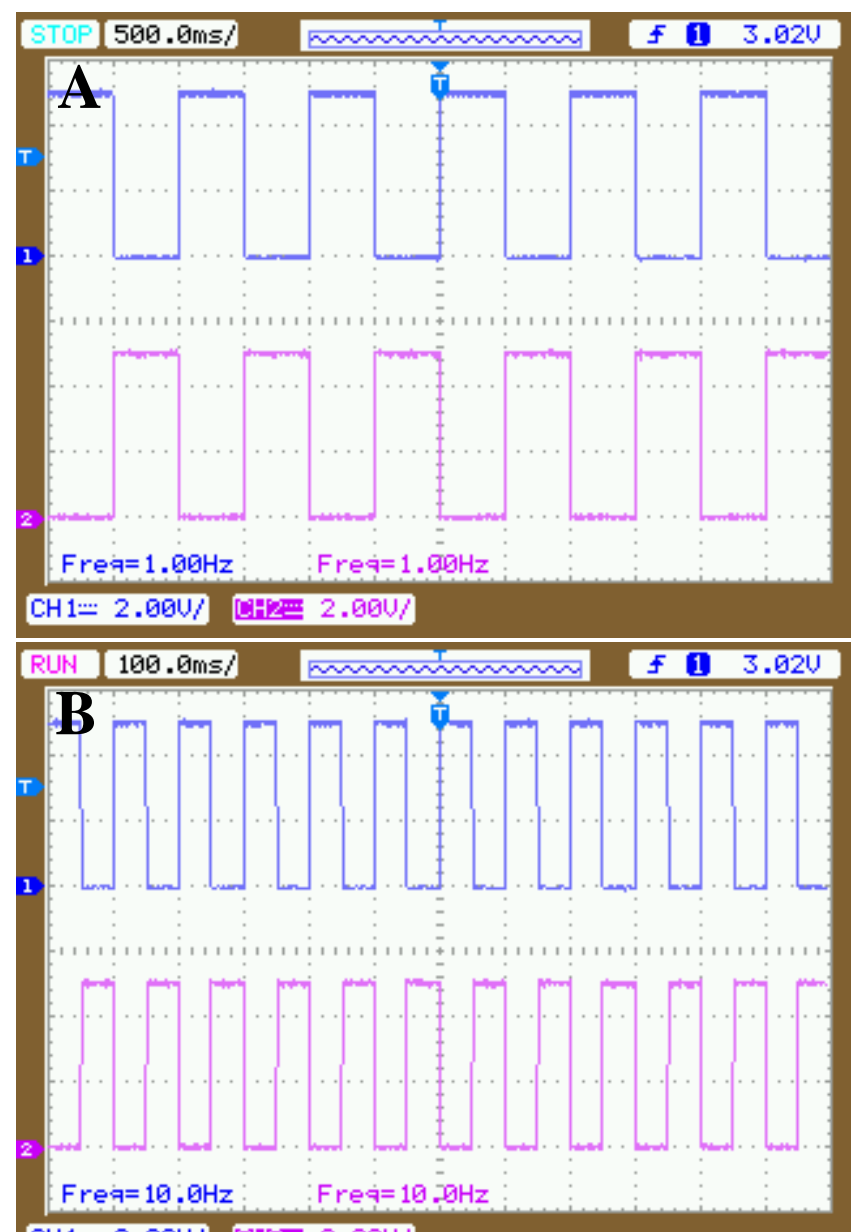

CH1ㄹ 2.000/ 대2픈 2.060/

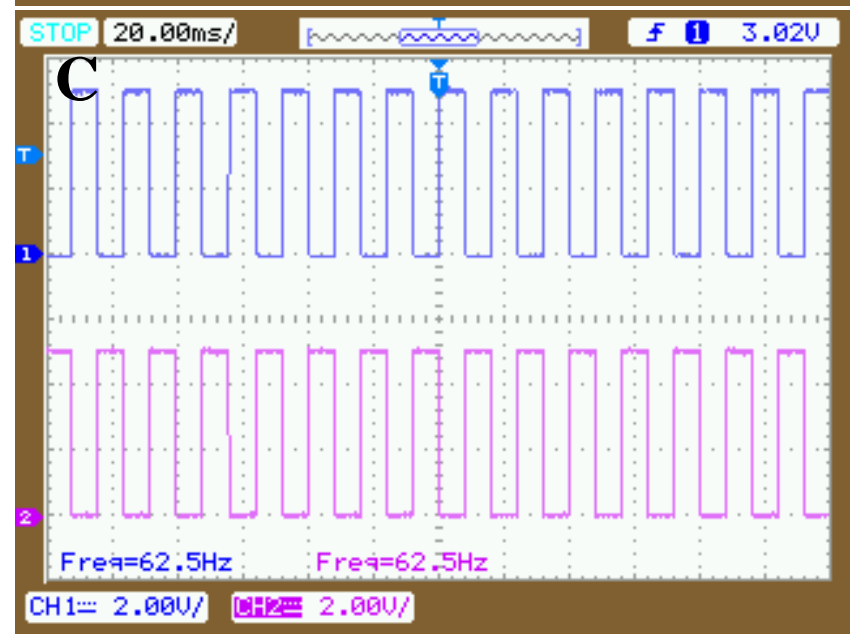

474 Figure 2. Control signals at $1 \mathrm{~Hz}(\mathrm{~A}), 10 \mathrm{~Hz}(\mathrm{~B})$ and $60 \mathrm{~Hz}(\mathrm{C})$. The blue curve is the 475 control signal for MOSFET M1 and the magenta curve is the control signal for MOSFET 476 M2. 


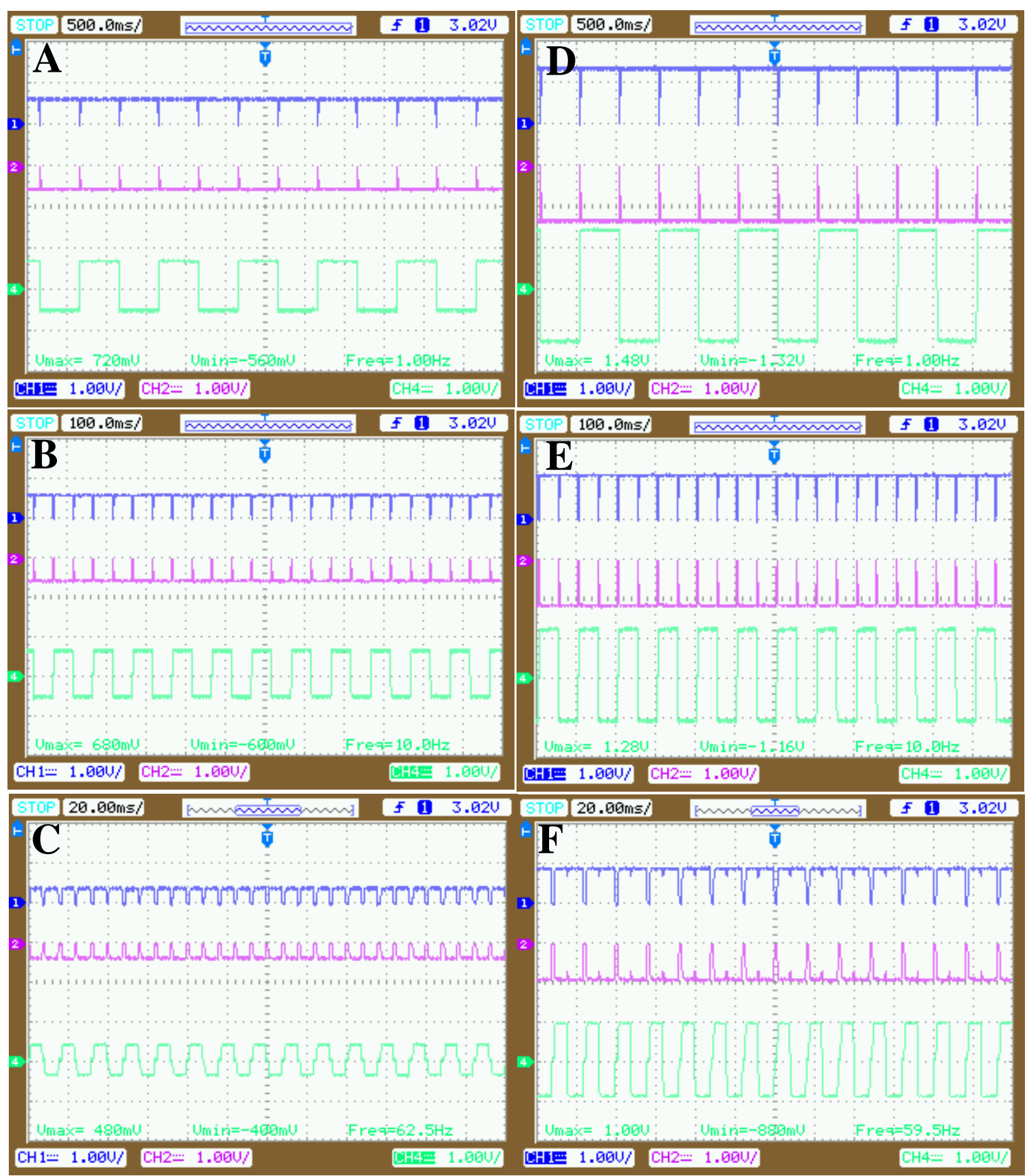

480 Figure 3. Input and output voltages without using energy storage layer (capacitors) in the 481 circuit. The DC-AC converter was powered by two MFCs at $1 \mathrm{~Hz}(\mathrm{~A}), 10 \mathrm{~Hz}$ (B) and 60 $482 \mathrm{~Hz}(\mathrm{C})$ or four MFCs (2 groups of $2 \mathrm{MFCs}$ in series) at $1 \mathrm{~Hz}(\mathrm{D}), 10 \mathrm{~Hz}(\mathrm{E})$ and $60 \mathrm{~Hz}(\mathrm{~F})$. 483 Blue waves: MFC1; magenta waves: MFC2; green waves: AC output. 

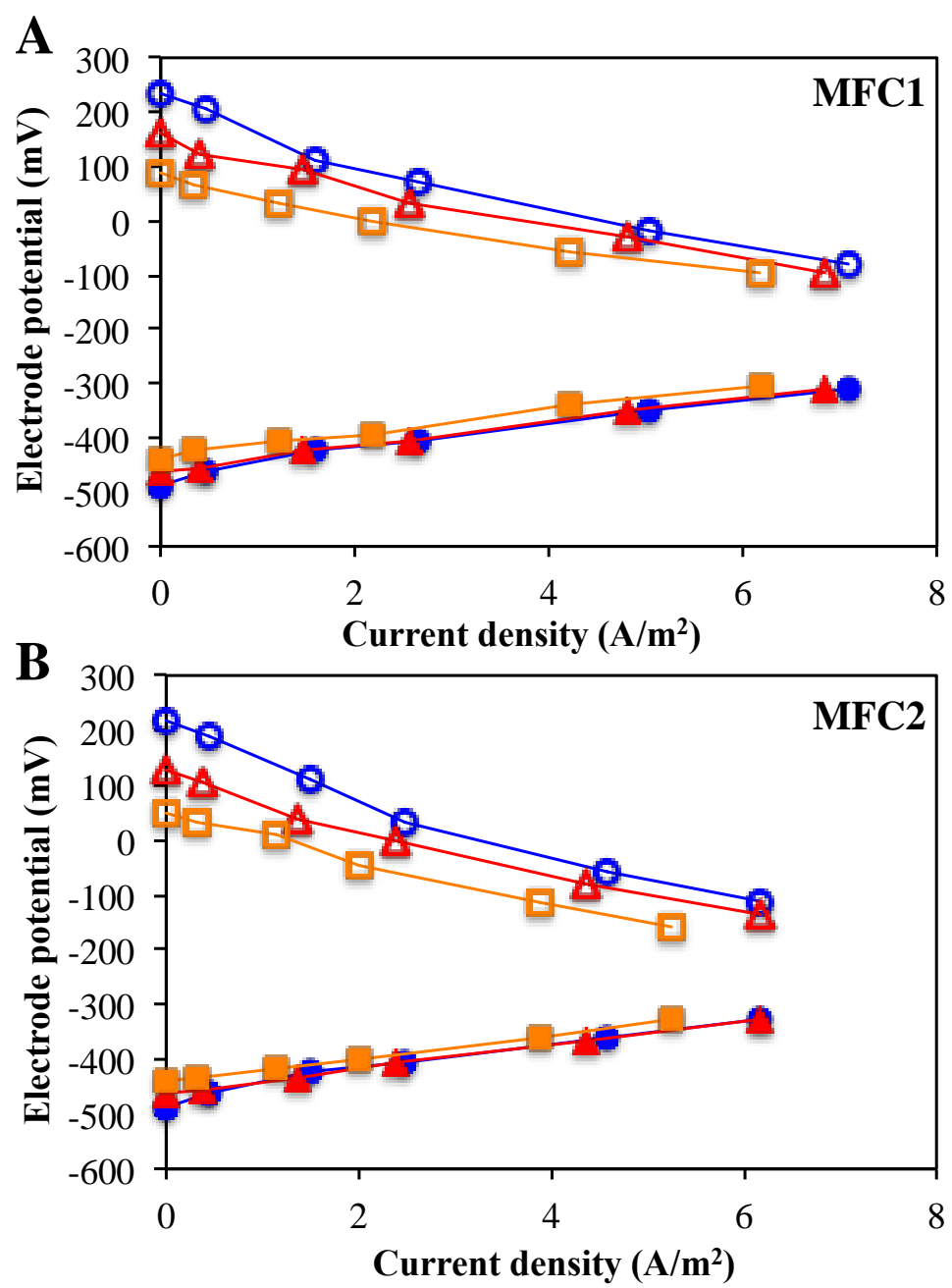

Figure 4. Electrode potential changes of MFC1 (A) and MFC2 (B) at frequencies of 1Hz, $49410 \mathrm{~Hz}$ and $60 \mathrm{~Hz}$ without using capacitors in the circuit. 


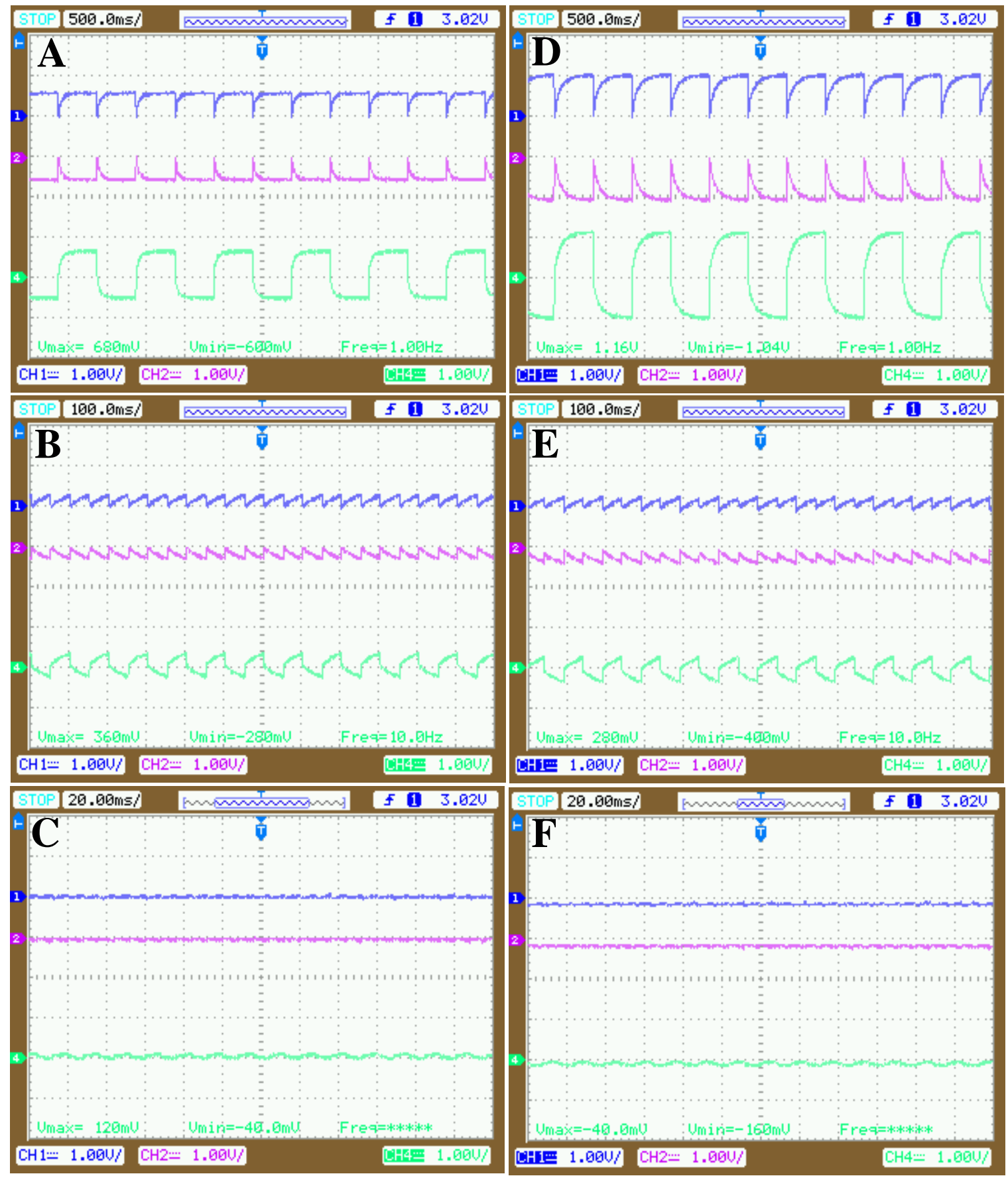

500 Figure 5. Input and output voltages when using energy storage layer (capacitors) in the 501 circuit. The DC-AC converter was powered by two MFCs at $1 \mathrm{~Hz}(\mathrm{~A}), 10 \mathrm{~Hz}(\mathrm{~B})$ and 60 $502 \mathrm{~Hz}(\mathrm{C})$ or four MFCs (2 groups of $2 \mathrm{MFCs}$ ) in series at $1 \mathrm{~Hz}(\mathrm{D}), 10 \mathrm{~Hz}(\mathrm{E})$ and $60 \mathrm{~Hz}(\mathrm{~F})$. 503 Blue waves: MFC1; magenta waves: MFC2; green waves: AC output. 

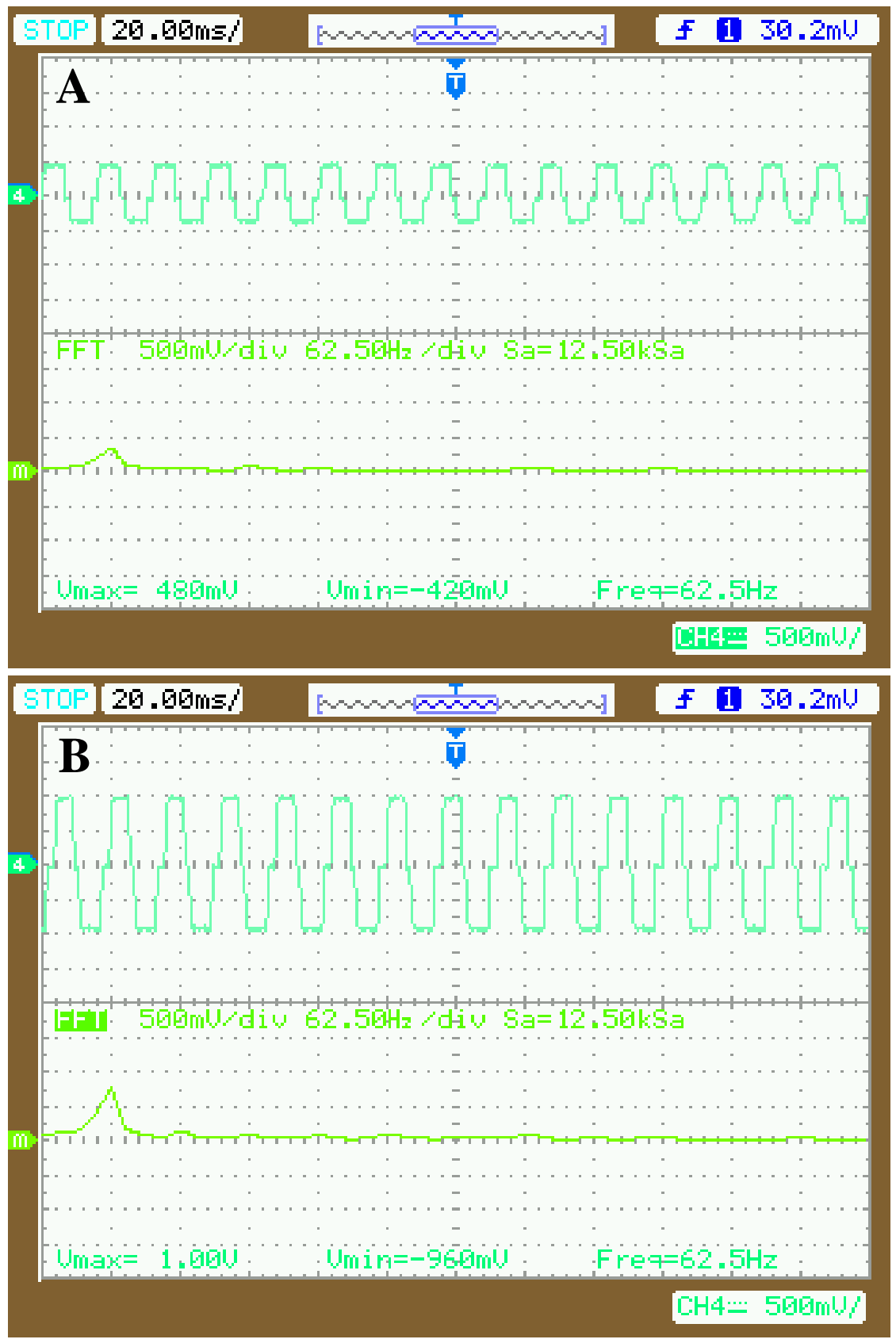

509 Figure 6. Output voltages and the Fast Fourier Transform (FFT) of the output voltages at $51060 \mathrm{~Hz}$ when the DC-AC converter was powered by two MFCs (A) and four MFCs (2 511 groups of 2 MFCs in series) (B). 


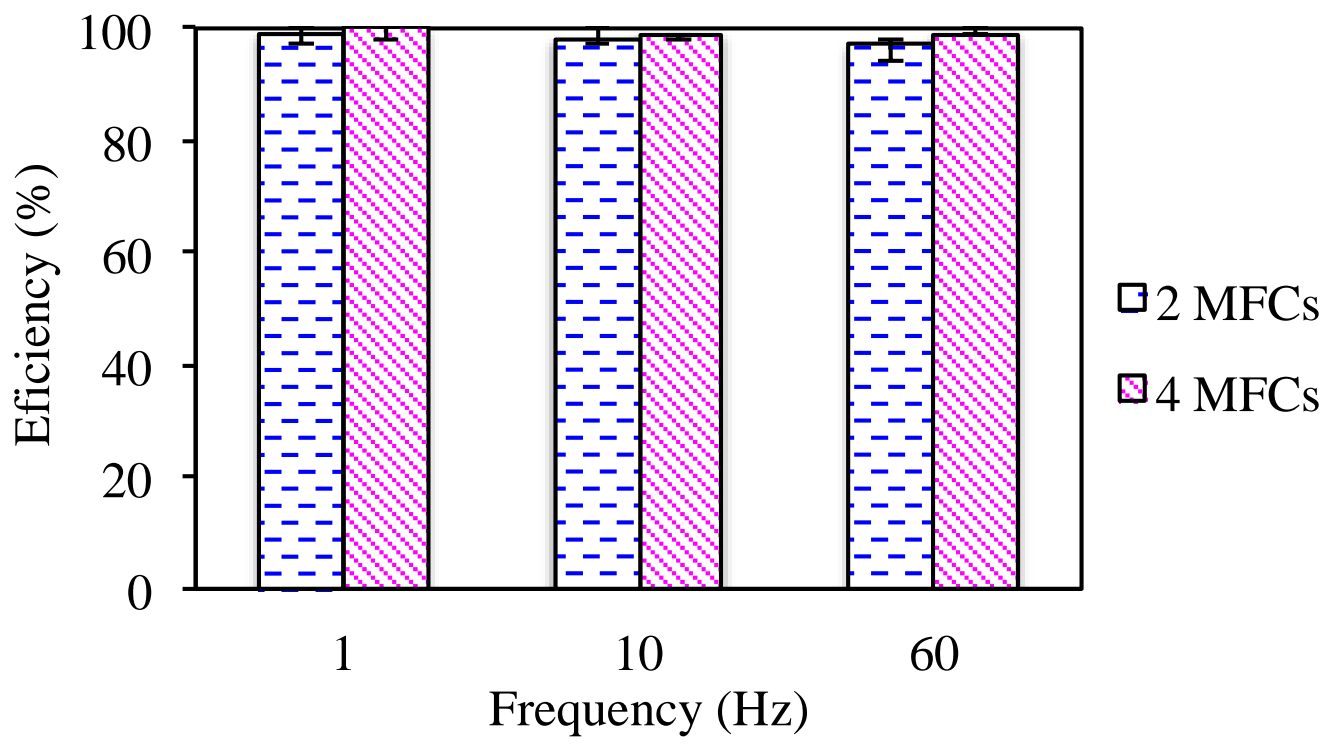

516

517 Figure 7. Efficiency of the DC-AC converter powered by two or four MFCs (2 groups of $5182 \mathrm{MFCs}$ in series) at $1 \mathrm{~Hz}, 10 \mathrm{~Hz}$ and $60 \mathrm{~Hz}$. 